\title{
A Structural Model for Player-Characters as Semiotic Constructs
}

\section{Daniel Vella}

\section{INTRODUCTION}

The question this paper sets out to answer is a simple, and, perhaps, rather obvious one, but one that, to some extent, game studies has shirked from confronting directly. It is this: what constitutes a playercharacter?

It might seem strange to suggest that the player-character is an underexamined theme in game studies. Even if consensus on the central questions is elusive, the discourse of the player-character is more or less clearly defined, with established dialogues, arguments and counter-arguments drawing upon a broadly stabilized set of concepts. On the one hand, we find the argument that player agency can be made to cohere to the nature of a predetermined character through the shaping of “dramatic agency” (Murray 1997). Conversely, we can also identify the reaction stating that the nature of the figure as a vehicle for player agency renders notions of character irrelevant: it "just becomes a "cursor" for the player's actions" (Frasca 2001), being understood purely in instrumental terms as a set of tools to be deployed by the player (Newman 2002). To this, in turn, is opposed the objection that "the steerable thing being discussed is a character, with an anthropomorphic nature and a character's place within the interactive fiction world” (Montfort 2007). Emma Westecott (2009) suggests an application of puppet theory to the player-character. More recently, the discussion has taken new inflections in Kristine Jørgensen's outlining of the conflict between player agency and the 
constraints of a fixed, predetermined character (2010), or Clara Fernández-Vara's signaling of a radical split between player and character (2011).

As divergent as these positions are, in all these cases, the focus of research has tended to be "the framing of the relationship between the player and her player character" (Westecott 2009, 2) - not on the character itself. As such, "player-character" is often linked to "avatar", in a recurring identification of a duality in the ontological nature of the anthropomorphically represented game entity under the player's direct control - a duality most fully mapped out by Rune Klevjer (2006, 10).

The entity behind this terminological duality, then, is a game component, one of the set of entities that constitute the game system. For lack of a better neutral term that lacks the implications of either "avatar" or "character", this entity shall be referred to as the playable figure (Vella 2014). Its being the only game component over which the player is granted direct control gives it the status of an "avatar" - and, on this front, there is no shortage of critical perspectives investigating its formal, ontological and phenomenal nature (a by no means exhaustive sample might include Newman 2002; Rehak 2003; Linderoth 2005; Klevjer 2006, 2012; Bayliss 2007; Jørgensen 2009; Waggoner 2009; Mukherjee 2012). However, the game component and the character are not the same thing, and, as Klevjer argues, "there is, for analytical purposes, a lot to gain from keeping 'character' and 'avatar' distinct” (2006, 116). "Lara Croft”, aristocratic British adventurer, is not the computational entity that responds to the player's input, to which a particular audiovisual representation is attached. Rather, as a character, she is a "possible non-actual individual” (Margolin 1990, 844), a member of a diegetic world. The game component over which the player is given control, together with its associated audiovisual elements, is only a sign that represents this possible individual, engaged in a semiotic process of signification that still needs to be mapped out. 


\section{WHAT IS A CHARACTER?}

By and large, when opposing "character" to "avatar" - and bracketing situations, such as James Paul Gee's description of the "virtual character" as "the player's surrogate" (2008, 259), in which "character" simply becomes another term for "avatar" - game studies has taken for granted the idea that "character" refers to the impression of an individual with its own identity, without considering how this impression is formed. Noting the consternation faced by players of Crysis (Crytek 2007) when the avatar suddenly begins to speak in his own voice, Jørgensen writes that "the avatar gives the impression of suddenly turning from being completely controlled by the player into being an individual and autonomous being with a will of his own” $(2009,3)$. In the same vein, Bayliss writes that "the avatar is also a character, that is, an entity constituted separately from the player" (2007, 2), and Fernández-Vara argues that the identity of a defined player-character "sets them apart from the player, emphasizing the gap between character and player" $(2011,13)$. While the existence of this independent individual - or, at least, the impression of it - is acknowledged, questions regarding its ontological make-up, and the formal techniques by which it is produced, have not been tackled to a sufficient degree.

Perhaps this is because characters - those "images of possible people" (Phelan 1989, 2) routinely encountered, not only in games, but also in novels and short stories, on TV, on stage or at the cinema are "so familiar a phenomenon that they do not seem to require closer inspection” (Eder et al. 2010, 3). However, literary theory in particular has, for some time, recognized that "once they are subject to closer scrutiny, characters prove to be highly complex objects" (ibid.). For this reason, an approach to the analysis of playercharacters must be built on solid conceptual ground regarding the more basic question, "What is a character?"

Since it is within the field of literary theory that this question has been most thoroughly tackled so far, it is in this direction that this paper shall turn first. The aim in adopting a literary-theoretical perspective 
on character is that of arriving at a foundational understanding of what is entailed in the notion of a 'character', which can then, in this paper's later sections, be used as the basis for mapping out an approach to the player-character.

The problem presented by the constitution of a character takes its shape in Uri Margolin's definition:

"Character" or "person" in narrative will be understood as designating a human or human-like individual, existing in some possible world [...] a Narrative Agent (=NA) to whom inner states, mental properties (traits, features) or complexes of such properties (personality models) can be ascribed on the basis of textual data. (1986, 205).

In other words, the problem lies in the necessity of bridging the gap that opens up between the impression received by the reader of a living, breathing individual, and the reality that, if we were to identify any concrete ontological existence for this individual, we would come up only with a limited set of textual signs.

This duality in the meaning of the term 'character' has led to a duality in theoretical approaches. As Henriette Heidbrink writes, there exists:

...a continuum between >abstraction « and >concretion`, whereas the first pole stands for the medial material, the text, the signs, or the structures of the medial product and the second pole stands for the character that is via reception perceived as a humanlike entity with a coherent self including an individual personality (2010, 72).

Heidbrink argues that a debate has taken shape along the lines of this dichotomy, between what she terms "humanistic" positions that focus on the analysis of characters as individuals that can, for critical purposes, be considered independently of the text, and those grouped under the banner of "formalists, structuralists and semioticians" (ibid., 73), who dismiss this impression of a human individual as an extraneous accretion to a set of semiotic data, and, as a result, develop 
a perspective according to which characters "dissolve into textuality”, in Shlomith Rimmon-Kenan’s phrase (1983, 31).

This dichotomy can be summarized, in semiotic terms, as one between an idea of character as a signifier and as a signified. Rimmon-Kenan puts it succinctly when she says the distinction is between understanding characters as "words" or as "people” (ibid.). It is in the apparently paradoxical co-presence of both understandings that the true ontological nature of a character is to be found. The irreducible individuality of a character as a possible non-actual individual, marked out by the proper name as its symbol, as well as by the essential nature that name stands for (Genette 1980), is an illusion constructed through an accumulation of textual signs, and, in understanding the nature of the character, its "verbal surface" is as crucial as the "suggestion and imitation of human life" it establishes (Price 1983, 57).

As such, it is in the apparently paradoxical co-presence of both understandings that the true ontological nature of a character is to be found. The impression of a human individual can only be understood in the light of the system of signifiers out of which it is generated, and the same set of signifiers only makes sense with reference to the total impression towards which it is oriented. Given that a set of semiotic elements within a text can only be grouped under the unifying aegis of a 'character' if the individual signs are, in the first place, recognized as pointing towards the same figure, then such a figure (to which one can only apply the label of a human individual, albeit not necessarily an actual one) must have been posited, and kept in mind, during the act of reading - a purely semiotic approach would thus be guilty of the a posteriori erasure of a unified figure that must necessarily have been already established in the act of reading for that reading to have taken place. It is in this light that, to use the terms suggested by James Phelan (1989), a character is both mimetic, a (re)presentation of a possible person, and synthetic, a textual construct constituted of signs (1989, 2). 


\section{A SEMIOTIC-STRUCTURAL MODEL OF A CHARACTER}

It is apparent enough, however, that in its basic constitution, a 'character,' if one were to adopt a bottom-up textual-analytical approach, is a semiotic construct, a figure that emerges through the accretion of a set of textual signifiers. It is necessary, then, to found an ontological understanding of the player-character, at the most radical level, on an identification of the signifying elements out of which it is accrued.

\section{Existing theorizations of the player-character}

It is hard to locate, within game studies, a rigorous theoretical framework by which such a task can be achieved. As with any rule, of course, exceptions exist: a survey of the relevant literature reveals three models that can be employed in orienting this investigation towards the task of achieving such an ontological understanding of the player-character. These are the approaches to the player-character proposed by Fernández-Vara (2011), Lankoski, Heliö and Ekman (2003) and Schröther and Thon (2014).

Fernández-Vara suggests a list of the "identity markers" of the playercharacters as being "name, image, animation, speech, back story" (2011, 10). While this is a start in determining the constitution of the player-character as a textual entity, it does not go far enough in taxonomizing the various avenues by which characterization might occur, nor does it account for the specificities of the character in question in its association with a playable figure under the player's control.

This was precisely the difficulty tackled by Lankoski, Heliö and Ekman in their earlier attempt to analyze the constitution of playercharacters (2003). Starting with reference to Rimmon-Kenan's discussion of the nature of literary characters, their model attempts to expand the understanding of the ways in which the determination of a character can also occur through game-specific means, suggesting the ways in which the 'player' side of the dual term 'player-character' 
must reshape the understanding of the 'character'. In this regard, their insights are invaluable, and shall be drawn upon throughout the course of this chapter. At the same time, however, non-ludic modes of characterization are bracketed and set aside from the main thrust of their analysis, missing the potential to arrive at a unified understanding of the specification of player-characters that fully integrates all possible avenues of characterization available to games as a hybrid form that also incorporates non-ludic medialities.

What remains necessary, then, is a model that weds Fernández-Vara's taxonomical approach towards the semiotic aggregation of the character's textuality to Lankoski, Heliö and Ekman's acknowledgment of the player's role in the constitution and determination of this textual whole. Arriving at such a model would appear to be Felix Schröter and Jan-Noël Thon's aim: their approach to theorizing the player-character is built on the observation that "the ways in which characters are represented in contemporary video games cannot and should not be reduced to either interactive simulation or 'predetermined' narration," given that the playercharacter "is constituted precisely by the complex interplay between these two modes of representation" (2014). This leads to the argument that there are three modes by which the 'character' in 'playercharacter' is conveyed: the mode of narration, the mode of simulation and the mode of communication. Moreover, these three modes of representation are linked to three dimensions of experience of the character: respectively, Schröter and Thon term these the "narrative experience," the "ludic experience" and the "social experience" (ibid.).

According to this model, mode of narration refers to the understanding of a character that most closely aligns with the understanding we have identified in literary theory. It serves as the basis for the narrative experience of the character, in which "the player perceives game characters as identifiable fictional beings with an inner life” (ibid.). The mode of simulation addresses the playercharacter's status as a game component within the game system, and establishes a ludic experience, in which "the player's attention is 
focused on characters as [...] game pieces that are defined by gamerelated properties such as 'health points', 'speed', 'special abilities' and so on" (ibid.). Finally, the mode of communication accounts for the fact that the player-character can, especially in the context of a multiplayer game, constitute a means of self-expression on the part of the player, leading to a social experience in which "players not only form mental models of a fictional being or game piece but also of the player 'behind' the avatar, resulting in a connected or mixed representation which includes features of both” (ibid.).

Schröter and Thon's argument, then, provides an insight into the multimodal nature of the player-character as a composite entity, defined by a tripartite ontology as "fictional entity, game piece, representation of the player" (ibid.)). However - despite the fact that their paper goes on to offer productive analyses of player-characters in Spec Ops: The Line (Yager Development 2012), The Elder Scrolls V: Skyrim (Bethesda Game Studios 2011) and Star Wars: The Old Republic (Bioware 2010) - their research stops short of integrating these multiple modalities into a unified structural model of the playercharacter as a semiotic construct. It does not, for instance, take into account how the ludic properties of a player-character might contribute to the concretization of the image of a human or humanlike individual, which is considered as operating purely through what Schröter and Thon term the mode of narration. For this reason, we shall now propose a new semiotic structural model of the playercharacter, in an attempt at bringing together these disparate dimensions of characterization.

\section{A taxonomy of "characterization statements"}

Arguably the most comprehensive and fully-developed structural model of a character is that proposed by the narratologist Uri Margolin. According to his model, the basic building-blocks of a character, on the textual level, are what he terms characterization statements (1986, 206). A characterization statement (hereinafter CS) is a textual cue from which some attribute or trait pertaining to a character can be inferred. As the reader engages with a text, she 
will encounter a sequence of CSs for any given character, and will interpret each CS as an insight into some aspect or trait of the character in question. Margolin refers to this process of "the ascription of individual mental traits” or factual attributes to a textual individual on the basis of an inference from a CS as characterization (ibid.).

A character is therefore always a product of a second-order process of signification - Margolin notes that a "character or person is a signified, for which some other textual elements serve as signifiers" (ibid.). Moreover, the inferential nature of characterization reveals a considerable level of ambiguity at work. Most CSs accommodate multiple readings - different, perhaps even directly contradictory, character attributes can be inferred from the same CS depending on how it is interpreted by the reader. This is the point made by Roland Barthes in his influential reading of Honoré de Balzac's Sarrasine:

"To read is to struggle to name, to subject the sentences of a text to a semantic transformation. This transformation is erratic; it consists in hesitating among several names: if we are told that Sarrasine had 'one of those strong wills that knows no obstacle', what are we to read? will, energy, obstinacy, stubbornness, etc.?” $(1974,92)$

This understanding leads us to conceive of a "character" as a mental construct arrived at by the reader, built up piece by piece, in puzzlelike fashion, through the gradual accumulation of CSs. This is the process that Margolin terms character-building, which "consists of a succession of individual operations of characterization, together with second order activities of continual patterning and repatterning of the traits obtained in the first order operations, until a fairly coherent constellation or trait paradigm has been arrived at” $(1986,206)$ - an observation which recalls Seymour Chatman's earlier delineation of a character as a "paradigm of traits" (1980, 126). As Rimmon-Kenan puts it, "if a common denominator, e.g. ambivalence, emerges from several aspects, it can then be generalized as a character trait, and in a similar way the various traits combine to form the character” (1980, 
38). The result of this is that "character can be seen as a tree-like hierarchical structure in which elements are assembled in categories of increasing integrative power” (ibid., 37).

Margolin's next step is to offer a taxonomy of the possible categories of CSs, thereby mapping out the semiotic foundations upon which the hierarchical signifying structure of a character is established. A caveat is necessary: the very term Margolin chooses - characterization statement - implies a mediality of character founded on linguistic propositions. As such, Margolin's taxonomy must be modified to fit the specificities of the player-character - not only through taking into account the fact that games, as "integrated crossmedia packages" (Aarseth 2012, 2), set in motion a polymodal semiotic presentation that can include visual, verbal, aural as well as purely ludic signs, but also, as Lankoski, Heliö and Ekman do, taking into account the role of the player in the determination of the textual unity constituting the player-character.

Nonetheless, Margolin's basic distinction between three categories of CSs - static mimetic elements, dynamic mimetic elements and formal textual patterns - is a solid initial stepping-stone in coming to terms with, and attempting to arrive at a comprehensive categorization of, the complete span of modes of CSs games afford in relation to their player-character/s.

This is the task to which the rest of this paper shall be dedicated. Though reference will also be made to a range of other games and player-characters, this categorization shall be framed through a close analysis of the player-characters in The Last of Us (Naughty Dog 2013) and Gone Home (The Fulbright Company 2013). The Last of Us - a third-person action-adventure game with a post-apocalyptic theme in which the player controls Joel, a hardened survivor, from a third-person perspective - was chosen as an example of a game whose high production values and adherence to the medial and generic conventions of audiovisual narrative result in a highly specified player-character constituted of a dense, multi-medial network of CSs. By way of contrast, Gone Home - a first-person exploration game 
in which the player takes on the role of Kaitlin Greenbriar, a young woman returning to her family home after a year in Europe - was selected in order to provide an opposite case, where the playercharacter is minimally specified and, if it is to emerge as a character at all, requires far more in terms of reconstruction on the reader's part.

Though the examples of Joel in The Last of Us and Katie in Gone Home shall form the foundation for the categorization of CSs pertaining to player-characters, a range of other player-characters in other games shall also be referred to as and when they become relevant. This shall serve both to contextualize the two primary examples, and to offer a wider perspective on the range of possible avenues of characterization relating to player-characters.

\section{STATIC MIMETIC ELEMENTS}

In Margolin's classification of CSs, static mimetic elements refers to statements regarding fixed (or relatively fixed) facts regarding a character, including "name, appearance, customs, habits, man-made and natural setting or environment” (1986, p.206). Of course, with respect to a literary character, these elements might change drastically over the course of a narrative. How much that is true of Jane Eyre at the start of Charlotte Brontë's novel, as a ten-year-old living in the Reed household, remains true of Jane Eyre, the experienced, financially independent woman at the novel's end? The same is true of player-characters in games, who are capable of undergoing radical transformation over the course of a playthrough while remaining, recognizably, the same character. For example, Jodie Holmes in Beyond: Two Souls (Quantic Dream, 2013) is glimpsed (and played) at various stages in her life: as a toddler, a young girl, a teenager and a young woman. In between these scenes, many of the static mimetic elements undergo radical shifts: her appearance changes, her costumes are different, her environment - and the role she plays within it - vary, and so on. Moreover, with specific reference to the category of static mimetic elements that are termed "ludic elements" below, we can note that "character development" as a game mechanic is a defining feature of the role-playing game genre. This 
demonstrates the fact that the mutability of player-characters is itself an accepted trope, and that the usage of the term static mimetic elements no more implies a rigidly unchanging nature for playercharacters than it does for literary characters - contrary to Frasca's suggestion that "most videogame characters would be flat" (2001, 1), a reference to the novelist E.M. Forster's definition of flat characters as those that "do not change throughout the course of the work" (1995).

With that caveat out of the way, we can propose a subdivision of static mimetic elements associated with the player-character into three categories. Represented elements shall refer to CSs delivered through audiovisual or linguistic signs attached to the figure in question. Contextual elements covers CSs that convey information regarding the character's place in their environment. Finally, mechanical elements describes the set of CSs which can be inferred from the structure of the figure as a game component.

Represented elements

i) Name

A player-character's name is often the first CS a player encounters. It can reveal the individual's gender and, to a considerable extent, their socio-cultural background - "Mario", for instance, signals the iconic plumber's Italian ethnicity. A character's name can also bear symbolic significance, being used to highlight important traits or attributes, or to reveal the character's function in the narrative think of how Gordon Freeman's surname in Half-Life 2 (Valve, 2004) signals his role as the "free man", striving for humanity's freedom in the face of the oppressive Combine occupation.

In Gone Home, the name Kaitlin Greenbriar (or its shortened form, Katie) lets us know that the character is female, and probably of Anglo-Saxon descent - an ethnicity that, in the context of the US in the 1990s, suggests, at the very least, the strong possibility of a life of upper- or middle-class privilege. As a derivative of "Catherine”, 
Katie's given name shares the Greek etymological root $\kappa \alpha \theta \alpha \rho$ ó (katharos), meaning "pure” - a fact which might color our initial impression of the kind of person she is. By contrast, in The Last of Us, the given name Joel - no surname is ever provided - seems to purposely reveal little about the game's protagonist, apart from a down-to-earth everyman quality. The lack of a surname - a quality which extends to all the non-player characters in the game, all of whom are referred to only by their first name - also serves to communicate the dissolution of societal structures in the game's postapocalyptic setting.

\section{ii) Physical appearance}

Along with the name, the player-character's physical appearance is often what constitutes the first impression of the textual individual that the player is encountering. With regard to our case studies, physical appearance plays a greater role in The Last of Us than it does in Gone Home. Given the latter's first-person perspective, combined with the slightly disconcerting lack of mirrors in the Greenbriar family home, the only images of Katie that the player receives are her passport photograph, and the family portrait hanging in the entrance hall. Apart from locating her, thanks to her hairstyle, in the game's period setting, these two images are most notable for their pointedly mundane quality, which aligns with Gone Home's general stylistic direction. In The Last of Us, Joel's appearance - full beard, weathered features, slim but muscular build, slightly graying hair, hard, clear eyes - gives the player more to go on. It is easy to detect an earthy, no-nonsense masculinity. It is just as easy to gain the impression of an individual who bears the mark of long suffering, who has been shaped by having to survive in his harsh, post-apocalyptic conditions, and whose best years are behind him.

\section{iii) Costume/s}

Lisbeth Klastrup and Susana Tosca have applied fashion theory to their study of players' choices when clothing their avatar in World of Warcraft (Blizzard Entertainment 2003), noting that "the way our 
characters look is important to us," being able to signal the player's status, group allegiances and individual style (2008, 4). Though this study was focused on the social role of costume in WoW's multiplayer environment, its central insight - that the outfit worn by a playable figure can serve (indeed, can hardly choose but function as) a rich layer of signification - is one that can be extended to the playable figures of single-player games. Again, the outfit/s a player-character wears can be indicative of many things. Costume can signal the character's belonging to a particular social group, nationality, organization or historical period - whatever gender, race and appearance the player chooses for Shepard in Mass Effect (Bioware, 2007), for instance, he or she wears the uniform of the SSV Normandy. Clothes can also highlight a character's adherence to a particular subculture - Ben in Full Throttle (LucasArts, 1995), with his biker's leather jacket and boots, is the perfect example - or associate a character with a familiar set of generic iconography, as Lewton's trenchcoat and fedora in Discworld Noir (Perfect Entertainment, 1999) locate him firmly within the detective-noir tradition, despite the fantasy setting in which he is placed.

Joel's plain, utilitarian work clothes associate perfectly with the masculinity of his physical appearance, adding to the impression of an individual who is oriented towards manual labor and physical action, and who gets his hands dirty. Their worn, stained nature also suggests having lived through hard times. Finally, his clothes also associate him with the Western genre, even further adding to the conglomerate of CSs which mark him out with such familiar - indeed, cliché attributes as "masculine", "tough" and "stoic". On the other hand, what little we see of Katie's outfits in Gone Home - in the family portrait, she is wearing a plain, formal black dress - provides us with little on which to base a CS.

iv) Voice

If a character speaks, independently of what they say, the nature of their voice - its physical qualities, any traces of an accent, vocal tics or habitual mode of speaking - can constitute a CS. Mario's 
cheerful disposition and Italian accent, at least since he was first voiced in Super Mario 64 (Nintendo, 1996), are major elements in his characterization, even on the basis of only a handful of phrases; and, in Thief: The Dark Project (Looking Glass, 1998), it is Garrett's frequent, characteristically gravel-voiced interjections that constitute one of the primary avenues of characterization. Even a lack of voice can in itself become a CS, as in the case of the notoriously tight-lipped Gordon Freeman.

Katie's only vocal utterance in the game is the message she leaves on the family's answering machine: this message is played at the start of the game, and is played again if the player chooses to listen through the messages stored on the answering machine. Her voice seems upbeat - she speaks rapidly and confidently. With The Last of Us, Joel's gruff, often mumbled vocal delivery emphasizes a reserved, somewhat introverted disposition - and we might be tempted to also detect a resigned weariness, which would chime with Joel's haggard appearance.

\section{v) Animations}

As Westecott notes, player-characters possess a pre-determined “constrained gesture set” $(2009,5)$, and the nature of this gesture set can affect the player's perception of the character to a great degree. The same action can be interpreted as revealing radically different character traits depending on how it is animated. Mario's joyful leap in Super Mario 64 and Nathan Drake's athletic but desperate, edgegrabbing scramble in Uncharted: Drake's Fortune (Naughty Dog, 2007) might animate what is, at heart, the same ludic action, but the difference in the attendant animation results in the action registering as a very different CS in the respective cases.

Once again, animations are not a factor at all in Gone Home. However, in The Last of Us, Joel's animations serve to reinforce many of the characteristics suggested by his physical appearance. His movements are heavy and deliberate, revealing a steady, meticulous character, but also one who performs actions swiftly, decidedly and 
forcefully. The gruesomeness of the animations whenever Joel performs a violent action - such as strangling a human enemy, or smashing a clicker's face in with a brick - are equally significant. We can read "confidence" and "experience” in the efficiency of the actions, and, in their cold brutality, also an indication of a character who has grown desensitized to the violence that is necessary for his survival.

\section{Contextual elements}

i) Possessions

The objects a player-character has in their possession can function as vehicles for CSs. In Beyond Good \& Evil (Ubisoft 2003), for example, Jade's possession of a camera metonymically indicates her journalistic professional background. This applies both to objects that are modeled as meaningful components within the game system, that can be picked up, used, carried in the character's inventory or be otherwise interacted with (what Aki Järvinen would term "components-of-self" $(2008,64)$ ), and to objects which are not part of the game system and exist only as semiotic "window dressing”: to use the ontological distinction proposed by Espen Aarseth (2007), both representational and represented objects can convey CSs as long as they are in some way associated with the character in question. In Deus Ex: Human Revolution (Eidos Montreal 2011), for example, the books lining the shelves of player-character Adam Jensen's apartment, even though they are little more than a texture on the wall, act as a particularly effective exposition for Jensen's interests and preoccupations.

At the beginning of Gone Home, the only objects in Katie's inventory are her passport and her flight ticket. Both items - together with the travel bag laid on the porch in front of her feet at the game's opening - serve to contextualize her arrival at her family's new home after a long period of absence, filling in the details of a year spent traveling around Europe. We might also read these as indications of an adventurous, open-minded personality. Joel's possessions, on 
the other hand, are comparatively scant, and constitute only what is necessary for survival in the hostile post-apocalyptic environment - a flashlight, a gun, a limited supply of ammunition. Again, the indication here is of an individual who, whether by natural inclination, by the demands of his situation, or by some combination of both, eschews anything but the bare necessities of survival.

\section{ii) Environment}

Much can be gleaned regarding a character based on the physical setting in which, by necessity or by choice, they find themselves. The idyllic, Arcadian milieu of Hyrule reveals as much about Link in The Legend of Zelda: Ocarina of Time (Nintendo 1998) as the opening tour of the Black Mesa Research Facility in Half-Life (Valve 1998) tells us about the kind of life led by Gordon Freeman. This is particularly true of games which allow the player to explore their character's home, an activity which, indirectly, becomes a means for the player to explore the character she is playing. Heavy Rain (Quantic Dream 2010), for example, uses domestic spaces as an efficient means of conveying its various player-characters' lifestyle, habits and preoccupations. Ethan Mars' personal crisis following the death of his son and his separation from his wife is expressed through a contrast between the bright, airy, clean-lined home he lives in at the start of the game, and the dingy, disorganized tenement he moves into after the incident.

At face value, Gone Home is a game entirely about Katie returning home - however, due to her family having moved house during her time in Europe, the house she is returning to is not, strictly speaking, her own. The room prepared for her is still unlived-in, full of stackedup boxes still to be unpacked. This frames Katie's traversal of the house as an exploration of an unknown milieu, rather than as the titular homecoming. Importantly, this aligns her unfamiliarity and curiosity about the space with the player's own, making it easier for the player to inhabit the subject-position she represents (Vella 2013). At the same time, this dissociation from her family home can also 
itself be read as a CS, revealing her traveler's alienation from the once-familiar setting she has returned to.

At the start of The Last of Us, the environment Joel has to exist in - the military-policed quarantine zone, with its strict rations and regulations, and the dangerous ruined city that surrounds it, ridden with armed bandits and with the infected - contextualizes much of what we have read into Joel's own representation, making more sense of his weathered appearance, his utilitarian clothes and possessions, his weary voice and his determination.

\section{iii) Role}

What is the character's role in their environment? Here we might consider such factors as a character's job or profession, their belonging to organizations or groups of any kind, and the relations between the character and non-player characters (NPCs).

As a college-age young woman from what appears to be a reasonably affluent family, Katie's decision to take a gap year and travel around Europe instantly frames her - however right or wrong this framing might be - as a recognizable stereotype. It signals "adventurousness”, but in a predictable, conventionalized gesture. More interesting are her relationships to the members of her family. We have already touched on Katie's alienation from her family resulting from her time away - though the postcards found throughout the house mark an effort to retain contact, and the personal comments addressed to individual members of the family suggest intimacy and a keen observer's eye. Moreover, Katie appears to play the role of a confidant to her younger sister Sam, who trusts her enough to share her deepest secrets and feelings with her.

At the start of the game, the player learns that Joel is a smuggler, working within a criminal underground to deliver goods through the borders of the quarantine zone. Later, when Ellie and he arrive in Pittsburgh and are ambushed by a gang of desperate bandits, Joel reveals that he had been involved in such ambushes on unsuspecting 
survivors himself in the past. This might lead the player to ascribe to him traits of amorality, unscrupulousness or - more mildly opportunism driven by necessity. However, during the course of the game, against the background of this shadowy past, Joel is, to a considerable extent, defined by his relationship with Ellie once she is placed under his care. It is on the ambiguous implications of the relationship - which can be called paternalistic and protective, but also, less charitably, possessive and obsessive - that Joel's characterization is founded.

\section{Ludic elements}

The sub-category of static mimetic elements we are terming "ludic elements" - with a reference to Schröter and Thon's discussion on the ludic attributes of the player-character (2014) - is a particularly interesting one, and, thus, warrants a preliminary elaboration. In the introduction to this paper, a crucial distinction was highlighted between the game component under the player's control and the character as a possible individual implied through a network of signification. However, it is precisely through being represented by a game component that the player-character gains one of its most prominent medialities. In other words, the attributes of the playercontrolled figure as a game component - its capabilities and limitations in relation to the other entities in the gameworld, the procedures by which it functions within the game system - can themselves become a vehicle for characterization. As such, unlike the other categories of CSs we have considered so far, CSs based on ludic elements, as the name suggests, operate through a mediality that is strictly unique to games.

\section{i) Capabilities and Limitations}

Considered as an avatar, the figure under the player's control is, to a great degree, defined by the capabilities it grants the player to affect the other entities making up the gameworld. This is the sense in which Newman speaks of avatars, instrumentally, as "sets of capabilities, potentials and techniques offered to the player" (2002), and in which 
Klevjer, drawing on Maurice Merleau-Ponty's embodied phenomenology, discusses the avatar in light of the "I can" it allows the player to direct towards the gameworld (2006). For our current purposes, however, what interests us is how these capabilities can be put in the service of characterization. Once we agree that the game component we have referred to as the figure can, when considered through a diegetic frame, be grasped as a character, then it must follow that its attributes as a game component, framed through the same diegetic perspective, must be understood as representations in a ludic mediality of that character's abilities in relation to their world - and, hence, an especially direct and revealing form of CS. The consideration of the figure's game-systemic affordances as defining the nature of a player-character as character also has an inverse aspect. If the player-character is defined by what they can do in the gameworld, they are equally defined by what they cannot do.

Though she does not specifically invoke the question of character, this is what Janet Murray hints at when she writes that, for interactive drama to be successful, "participation in an immersive environment has to be carefully structured and contained [...] the range of allowable behaviors should seem dramatically appropriate to the fictional world” (1997, 106). In this regard, Lankoski, Heliö and Ekman state that "limiting a player's freedom is an effective and frequently used method of creating personality to [sic] the protagonist character” (2003, 2); Nick Montfort writes that the player-character should be understood as "a constraint and possibility defined by the author, within which the interactor is bound to a particular perspective and a particular set of capabilities” (2007, 145); and Peter Bayliss argues that the limitation of the playable figure to a predefined set of action possibilities "highlight that the avatar is also a character" (2007, 2).

In a later paper, Lankoski expands on this point, engaging in an analysis of the fighting game Dead or Alive 3 (Team Ninja 2001) that takes as its starting-point the observation that "each selectable PC [player-character] attacks differently” (2011, 298). This leads, he argues, not only to a ludic differentiation between the various 
playable figures, each of which, in the fighting game tradition, grants the player idiosyncratic tactical advantages and disadvantages - with some, for instance, having slow but powerful attacks, while others are defined through nimble movement. Lankoski's argument is that Dead or Alive 3's "predefined functions and possible and impossible actions (i.e., the kinds of attacks a character is able to do)" allow it to "distinguish different PCs from each other," (ibid., 300) not only as game components, but also as characters. The reason for this is that it is the actions available to her through the particular playable figure she has chosen that will determine:

...whether a player will try to fight using counterattacks, powerful attacks, or faster and weaker attacks. Consequently, a player will project intentions to the character, and those projected intentions are likely to influence the perceived personality of the character. (ibid., 298)

Lankoski's insight here is indispensable, not only insofar as it highlights the manner in which the playable figure's capabilities and limitations act as meaningful CSs, but also in paving the way for a discussion I shall soon move on to: namely, that of accounting for the way in which actions performed by the player can be taken up in the service of characterization.

Katie's capabilities in Gone Home do not go far. Apart from the basic spatial abilities of looking and moving conventionally associated with the first-person perspective, the only capabilities she has are picking up and examining objects in the environment, and interacting with household objects by means of a single, context-sensitive "use" command (for instance, turning light switches on or off). Where Katie's abilities go beyond this basic set is in her capacity to scrutinize objects: when Katie picks up an object, she can zoom in to examine its details, and rotate it to view it from every angle. With progress in the game depending on scouring mundane items crumpled notes and receipts, old magazines and school assignments - for clues, this close scrutiny becomes a major aspect of Katie's 
character, as we perceive it in the game: we might deduce from this a CS defining Katie as a good observer, or as a meticulous personality.

Joel's capabilities in The Last of Us are largely defined by the game's adherence to the third-person action-adventure genre. As such, the ability to walk, run, move stealthily, take cover, use firearms and engage in melee combat constitutes the standard set for this genre: if we are to identify any meaningful CSs here, they must lie either in idiosyncratic emphases or nuances within this conventionalized set, or in the way(s) in which these affordances are contextualized. In the first case, the two additions to the generic action-adventure set of affordances are Joel's "listen mode" - effectively similar to x-ray vision, allowing the player to identify the locations of enemies hidden behind walls - and his ability to pick up the discarded bottles or bricks littering the gameworld and put them to a variety of uses, throwing them to create a distraction or using them as projectile or melee weapons. Taken together, these affordances emphasize a strong sense of spatial and environmental awareness, privileging careful, studied planning. In the second case, the orientation of the essentially violent set of affordances towards a setting which, as we have described, is almost constantly life-threatening frames the violence, at least initially, as necessary, desperate self-defense rather than as unwarranted aggression - though, as these acts of violence accumulate and escalate throughout the course of the game, the player might be forced to reconsider this initial assumption about Joel's attitude towards his own violent acts.

\section{ii) Passivities}

It is not enough to consider what the player-character can and cannot do in its relation to the other entities in the gameworld. Crucial to their status as individuals inhabiting a world is their capacity to be influenced by other entities in the gameworld. Klevjer illustrates this point by arguing that Lara Croft is not only defined by the "ability to jump or walk", but also by being open to the "risk of falling down the ravine” $(2012,18)$. As such, player-characters are also defined by what we might term their passivities - the ways in which they are 
passively open to the influence of other entities in the gameworld. Most often, this influence is a negative one, as in Klevjer's example, but it is not necessarily so.

Once again, Katie appears to be quite limited in this regard: she is not physically affected in any way by any other entity in the gameworld. Joel, on the other hand, is vulnerable to a great number of threats presented by his post-apocalyptic milieu and its inhabitants. A face-to-face encounter with the more dangerous types of infected frequently results in instant, unavoidable death. There are also numerous environmental threats: areas infected by fungal spores require Joel to put on his gas mask or risk infection, and he is also liable to drown in the frequent sections where he must venture underwater to clear a path ahead. This fragility in the face of an extremely hostile environment further contextualize Joel's affordances, framing them even more clearly as the necessary way of life he has had to adopt in order to survive.

iii) Goals

The player-character's capabilities are not meaningful in isolation: they gain their significance through being set to work towards a goal or set of goals (Vella 2013, 6). The same is true of passivities, that only gain meaning through being understood as hindering or facilitating the achievement of the goal/s in question.

These goals - whether set by the game or self-imposed by the player - are, by definition, the player's own, ludic goals. At the same time, however, they can also be attributed to the player-character as a distinct individual: this results in what Lankoski termed a "goalrelated engagement” between the player and her character (2011, 297). More importantly for our current purpose, this means that the ludic goals assigned to the player, when grasped as the playercharacter's goals within the gameworld, can serve as yet another CS layer - "goals are a very powerful tool of presenting the nature of a character” (Lankoski, Heliö \& Ekman 2003, 5). 
Katie's goal in Gone Home is investigative: she is placed in the detective role in a textbook example of an embedded narrative structure (Vella 2011, 8), piecing together events that took place before her arrival on the scene. Her goal, then, is to deduce the events that have taken place in her family's life during her time away. As a CS, this is open to being read in a number of ways: it could be interpreted as connoting nothing more than an idle, detached curiosity on Katie's part, or it could be read as her displaying worry and concern for her missing sister.

Joel's overarching goal is to protect Ellie, and to escort her safely to the end of the game: this frames his capabilities for action and violence in a very different perspective compared to if these capabilities were employed towards ensuring only his own survival. Where these capabilities - and the actions that result from putting them to use - could have been read as simply demonstrating a fierce hunger for survival and a drive for self- preservation, they are instead recontextualized as demonstrating paternal care and protectiveness.

\section{iv) Attributes}

Player-characters are also determined, in a perhaps even more direct manner, by means of their statistical attributes. These can be made available to the player as direct statistical values - as in the case of most RPGs - or they may become evident to the player ecologically, by witnessing the character interact with the gameworld and drawing conclusions. In the fighting game Soul Calibur (Project Soul 1999), for example, the player can note that Taki moves around the arena much faster than Astaroth: thus, while the underlying statistical values that define each character as a game component remain at the level of the unseen game system, simple observation of the game in progress is enough to reveal the presence of these values.

Unlike the other categories of ludic elements, attributes only have the possibility of serving as meaningful CSs if they can be compared to those of at least one other (player or non-player) character: their significance is relative rather than absolute. The player might realize 
she has been playing a character with a particularly high strength value only when she switches to playing a character with a much lower value for this particular attribute, which provides her with a point of comparison she would not have had otherwise. A character's slow movement might simply be a function of the given game's general slow-paced nature: it can only become the basis for a meaningful CS ("This is someone who moves slowly") if a character who moves around the world faster makes the first character's sluggishness significant by contrast. While Taki's speed is a meaningful CS when contrasted with Astaroth's relatively unwieldy movement, it makes little sense to compare Taki's movement to that of Chun-Li in Street Fighter IV (Capcom, 2009), since the attributes of the respective characters address entirely different game systems.

There are significant exceptions to this general rule: visible statistical attributes might provide the basis for an internal comparison between an individual character's strengths and weaknesses. Imagine the situation of encountering an RPG player-character about which nothing is known except that he possesses a Strength value of 18 and an Intelligence value of 6; or, conversely, a player-character with the reverse of those values. Even without knowing how these values compare to those of other characters in the game, a player with even a passing knowledge of the conventions of the genre will have no trouble finding ready stereotypes to draw on in order to flesh out this basic level of information into an image of a possible individual. Based only on this information, the player might guess that the first character belongs to some form of melee-combat-focused warrior class, such as a barbarian, while the second would be likely to be a magic user, possibly a wizard. Given that each of these stereotypes brings with it a whole range of assumptions regarding, for instance, the physical appearance, dress, habits and behavior of the individual in question, the power of attributes as a vehicle for CSs becomes particularly evident.

The second exception by which statistical attributes might become meaningful CSs even with no other characters present upon which to base a comparison is in the situation where a character development 
system - a point I shall examine below - allows the player-character's set of attributes to change over time. As such, the present configuration of the player-character's statistical attributes might gain significance in contrast to an earlier configuration, or to possible choices along the branching tree of character-development options that were not selected.

Katie in Gone Home has no visible attributes, and, with no other characters present in the game, no points of comparison are available by which her attributes might be brought into relief: as such, no CSs can be identified for Katie in this category. In The Last of Us, meanwhile, Joel is defined through a number of attributes: maximum health, listen mode distance, crafting and healing speed and weapon sway, as well as mastery of the various categories of weapons available to use in the game.

\section{DYNAMIC MIMETIC ELEMENTS}

In Margolin's model, CSs addressing dynamic mimetic elements are those which refer to "verbal, mental or physical acts" performed by that character $(1986,206)$ : actions serve as indexical signs for particular traits in the individual personality by which they are produced. Margolin argues that this is true not only of physical acts, but also of verbal acts - referring not just to the linguistic content of a character's speech, or even to paralinguistic elements such as tone of voice, but, rather, subsuming both to an understanding similar to John Searle's speech-act theory (1969). If we are also made privy to the character's inner life, then purely mental acts (what a character thinks, decides, plans, wonders, etc.) can also constitute meaningful CSs.

In relation to the characterization of the player-character, it is necessary to make a distinction between two sub-categories of CSs addressing dynamic mimetic elements. We shall term these subcategories character actions and player actions. 


\section{Character actions}

This constitutes the less conceptually problematic of the two subcategories of dynamic mimetic elements. In most games, there is a set of actions performed by the player-character without any input from the player. This might include, for instance, actions the player sees the character perform when she is, to use Newman's terminology, “off-line”, not actually playing: for instance, during a cutscene, or in the form of an idle animation that is triggered if a certain amount of time elapses without player input - Sonic's impatient foot-tap in Sonic the Hedgehog (Sonic Team, 1991) is a particularly iconic example of the latter. The verbal acts that constitute a character's voice-over - such as Garrett's vocal interjections in Thief - would also be considered under this category. This can also include actions taken by the character during play - that is, to use Newman's term, during the player's “in-line” engagement (2002); while exceptional, cases exist where the player-character refuses to follow the player's input, perhaps performing a different action of their own accord. Guybrush Threepwood in The Curse of Monkey Island (Lucasarts, 1997) is representative of this. Such actions are unequivocally to be attributed to the character rather than the player, and, as such, can easily be taken as strong CSs whenever they occur.

With no cut-scenes or other form of off-line sequence, the instances in Gone Home in which Katie performs an action of her own accord are few - in fact, precisely six in total - but revealing. Mostly, these fall under the category of mental acts, representing Katie's thoughts on the situation at hand by means of short text interjections on-screen. One of the first objects found in the course of the game, concealed in a trunk on the porch, is a duck-shaped festive ornament. When the player picks it up, we read Katie's thought on the matter, which is simply, "Good ol' Christmas duck" - a throwaway statement that reveals Katie's nostalgic relief at returning home after her time away.

The remaining character actions build a clear, linked pattern. When searching her father's library, the player-as-Katie finds pornographic magazines hidden in a box beneath copies of his novel. Here, Katie's 
thought, marked with, we might imagine, embarrassment or disapproval, is, “Gosh, dad.” The situation is repeated, to cumulative, even comic, effect, when a risqué magazine is found hidden at the bottom of the wardrobe in Sam's room ("Gosh, Sam”). Later, if the player decides to look through the drawers in Katie's parents' bedroom, a condom is discovered in the underwear drawer ("Gross") and a self-help guide to improving one's married sex life is found in the ensuite bathroom ("Ugh").

Already a pattern is established that defines a distinct character trait, albeit one that the player might construct in various ways: as a sign of Katie's discomfort about sexuality, for instance, or, more specifically, as embarrassment at discovering her family's intimate secrets. The most noteworthy character action on Katie's part, however, is the final one, occurring when a torn-out page from Sam's diary is found crumpled up in a waste paper basket. When the page is picked up, it is, as usual, displayed on-screen; however, the player is barely given enough time to skim the first few sentences, and get an idea of the subject of the page - in which Sam describes her erotic feelings towards Lonnie as their relationship grows more intense - before the page is automatically closed, with Katie commenting, "Okay, that's enough of that." If the player tries to "use" the note again to continue reading, Katie flat out refuses to do so, giving only the comment: "I...no."

Where Gone Home is minimal in terms of character action, The Last of Us is maximal. Thanks to a wealth of cut scenes, as well as to Joel's numerous pre-scripted in-line conversations with Ellie and other NPCs, many of the actions that prove most crucial to Joel's characterization are character actions that are not the result of player input. As a result of this, there are far too many individual character actions for us to present an action-by-action analysis on a similar level of granularity for the game as a whole. Instead, to provide an illustrative example, we can focus on a sequence of crucial character actions which occur in the game's closing moments.

Rather than allowing Ellie to be killed in a medical experiment to 
extract the source of her immunity, Joel violently infiltrates the headquarters of the Fireflies organization in order to rescue her, finally killing Marlene, the leader of the Fireflies, in cold blood to prevent her from ever attempting to track them down. Subsequently, he lies to Ellie about these events, leading her to believe the Fireflies let her go because there was no way of using her immunity as the basis for a vaccine. This sequence consists of a number of distinct acts which are crucial to the determination of Joel's character:

i) Joel decides saving Ellie's life is more important than a chance to obtain a cure for the fungal epidemic that is driving humanity to extinction.

This mental act can be read as the final indication of his fatherly devotion to Ellie - a devotion which can be linked to the loss of his own daughter in the first days of the plague. Less positively, it can be read as the sign of his obsessive need to atone for his perceived failure to protect his own daughter, being willing to potentially put the entire future of humanity at risk in order to fulfill his own emotional need to care for Ellie.

\section{ii) Joel shoots Marlene.}

This physical act, while, superficially, no different from the many murders Joel has committed during the course of the game in order to survive himself and to protect Ellie, bears a pronounced dramatic effect. Through Marlene's own characterization, she has been framed as level-headed, sympathetic, and idealistic; we learn that her decision to allow Ellie to be operated on was agonized over, leaving her wracked with guilt and self-doubt. In her confrontation with Joel, she is determined, but reasonable, conciliatory, and non-violent. Moreover, as the leader of the Fireflies, Marlene appears to embody one of the main hopes for the establishment of an alternative postepidemic social arrangement to the military's totalitarian rule. Joel's decision to kill Marlene in cold blood when he realizes he cannot sway her therefore serves to reinforce the traits of obsession and ruthlessness that have already been suggested. 
iii) Joel lies to Ellie about what happened.

This verbal act can be interpreted as a final instance of Joel's paternal attitude towards Ellie, shielding her from the guilt and self-doubt she might feel if she knew the truth. On the other hand, we might just as validly read this final action - with which the game ends - as a means for Joel to avoid confrontation with Ellie and to keep her enmeshed to him in a paternal relationship on which he has become emotionally dependent.

\section{Player actions}

In the vast majority of games, however, those acts we have defined as character actions constitute no more than a very small sub-set of the complete set of actions we can attribute to the player-character. Much more numerous are those we are terming player actions, being dependent on player input and, as such, unlike character actions, being perceived by the player as being her own as much as they are the character's. The fact that this category of dynamic mimetic elements - which corresponds to what Schröter and Thon termed "ludic events" in distinction to the scripted events of the predetermined narrative (2014) - is labeled "player actions” is not in any way meant to insinuate that these actions are to be considered less relevant to characterization. It is only meant to differentiate these actions from those character actions which are performed independently of the player. As Rehak (2003, 107), Ryan (2006, 190) and Westecott $(2009,1)$ point out, games re-present to the player a mediation of the game actions she herself performs; as such, player actions themselves become signs in the semiotic structure of the game, and, in the process of characterization, are weighed just as much as character actions: "as the player controls the character, the actions the player takes in the game also define what the character is like” (Lankoski, Heliö and Ekman 2003, 3).

There is clearly a link between the sequence of actions performed by the player in the course of playing a game, and the set of affordances linked to the figure as a game component, which we have already 
discussed as, in itself, a potential avenue for CSs. The former, we can say, is an actualization of the latter: out of the set of affordances available to her, the player, in the act of playing, actualizes a particular sequence of actions. Even if there is some room for the player to choose which actions to perform and which to avoid, she is always inescapably enacting one out of a limited set of actualizations of a given player-character. Here, it might be useful to recall Murray's prescription that "participation in an immersive environment has to be carefully structured and contained," in the sense that "the range of allowable behaviors should seem dramatically appropriate to the fictional world” $(1997,106)$.

Katie, as befits someone in the role of an investigator unearthing an embedded narrative (Vella 2011), is primarily receptive - she searches, she reads, she moves from room to room trying to piece clues together. It could be argued this further emphasizes the sense of estrangement and alienation she feels towards her family after her time away, and her desire to reconnect with their lives. Meanwhile, the player's actions as Joel - with play following a pattern of exploration of a sequence of environments in search of supplies, alternating with encounters with enemies that can be approached with stealth or with brute force - again play into the set of character traits we have identified: his methodical, structured awareness of the situation, his ruthless efficiency and his level-headed approach to dangerous situations are all enacted in play. Furthermore, in the player's constant need to be aware of Ellie's location and status during combat - initially in order to ensure her safety, but, as the game progresses, also, increasingly, as a tactical ally - we can read both an underlining of Joel's protective, paternalistic attitude towards Ellie, and also the gradual (but never complete) shift in his attitude towards her as he begins to trust her with more responsibility.

\section{FORMAL TEXTUAL PATTERNS}

This is the most vaguely defined category in Margolin's taxonomy, covering "grouping of [narrative agents]; the analogies, parallels or contrasts between them created by such groupings; repetitions or 
gradations, and various stylistic features associated with their introduction or occurrence" (1986, 206). Here, we shift focus: from looking at what about a character is represented, here we look at how it is represented, paying attention to formal techniques and the deployment of aesthetic, generic and medial codes.

A couple of examples of the kind of formal techniques which might be included in this category might suffice as an illustration. We might consider, for instance, the extent to which Katie's characterization is driven by a sustained contrast between her and Sam. This is most evident in the juxtaposition of their images in the family portrait: aspects of Katie's appearance which appeared neutral or unremarkable in isolation gain semiotic relevance through contrast with Sam. Katie's stylistically conservative black dress stands in contrast to Sam's flannel shirt, which aligns the younger sibling with the grunge and riot grrrl subcultures. Sam's androgynous outfit also serves to make the relative femininity of Katie's dress semiotically relevant. Moreover, other explicit parallels are made throughout the game. At different points, the player finds copies of the same homework assignment - a biology exercise in which sentences have to be placed in the right order to give an account of the female reproductive cycle - filled in by both sisters. Katie's assignment is filled in correctly; Sam's incorporates the sentences into a Second World War narrative in which the protagonist's fiancé is killed in a bombing raid, paralleling the protagonist's grief and subsequent resilience to the biological process of menstruation and ovulation. The CS that is implied in the contrast between the two assignments Katie as straight-laced, Sam as artistic and rebellious - is obvious.

In the opening scene of The Last of Us, a common formal technique for introducing the player-character is exemplified in a particularly striking fashion. Initially, the player is given control of Sarah, Joel's young daughter: as such, the player's initial experience of Joel is an external one. This prologue plays a vital role in Joel's characterization - not only because Sarah's death at the end of the sequence allows us to consider long- gestating sentiments such as grief and guilt as being central to Joel's character, but also because it presents Joel to 
the player in the mode in which, once the player takes control of him, he will adopt towards Ellie: paternal, protective, level-headed, resourceful. In essence, before the player picks up Joel's controls, he has already been established as a character through being framed from an external perspective - an effect similar, if more pronounced, to that which is often achieved in games through an intro cutscene.

\section{THE 'PLAYER' IN 'PLAYER-CHARACTER'}

By their very nature, characters are never available to us as figures whose outlines are completely shaded in - as Price notes, "fictional characters are only partially specified” $(1983,57)$. Having completed both games and seen the processes of characterization and character building through to the end, there remains much we do not know about Joel and Katie. This applies not only to background biographical detail - say, where Joel was born, or what Katie's favorite food is - but also to aspects of the respective characters that are crucial to the events occurring in the course of the game. It is never specified, for instance, whether Katie, in piecing together the details of Sam and Lonnie's relationship, shares their parents' disapproval of the same-sex relationship, or whether she holds a more open-minded attitude on the issue.

To a great extent, of course, this is due to the inevitable fact that characters are, by their very nature, "ontologically 'thin' and not maximal, having only a limited number of properties and relations” (Margolin 1990, 847). However, there is an additional factor at play here. Though it has been the focus of this paper to arrive at a semioticstructural model that addresses the player-character as a composite of textual signs in all the various medialities offered by a digital game, the question of the role of the player in this process needs to be acknowledged. After all, it is on the crucial point that a character does not exist as a fully defined semiotic entity until actualized by player input that the ontological nature of the player-character is set apart from other formulations of character.

Both as an indication of how the model we have proposed can fit 
into a more complete understanding of the player-character, and as a signpost towards future directions for theorizing the player-character, we shall briefly consider two important insights that result from a fuller consideration of the role of the player. Firstly, the player always has some degree of input, no matter how minimal, in the shaping of the set of CSs that constitute a player-character's textual substrate. Depending on a particular player's actions, different playthroughs might produce very different sets of player action CSs, and, hence, different characterizations. A player of The Last of Us might favor Joel's affordances for stealth and spatial awareness, patiently assessing every situation and avoiding confrontation and violence where possible. Another player might instead make a point of eliminating every hostile individual encountered. The available affordances allow for both styles of play, but the Joel that results from the first playthrough is, in an important way, different from the Joel that results from the second, even with all the other CSs that go into his constitution remaining unchanged.

This renders the player-character, as a semiotic construct, incomplete in an entirely different sense to the incompleteness of character identified by literary theorists like Margolin, Price or Alan Palmer, who writes that a character only exists as a character once the reader "collects together all of the isolated references to a specific proper name in a particular text and constructs a consciousness that continues in the spaces between the various mentions of that character" (2004, 176). This difference is predicated on the ergodic nature of game textuality (Aarseth 1997): since the user function of the player, unlike that of the novel reader or the film viewer, is configurative rather than purely receptive, the complete set of CSs that constitute a player-character's textual substrate is not present and accounted for from the start - as it would be for a character in a novel or a film - but is only fully determined once the player's selections and ludic actions have traced out a path of traversal through the network of possibilities offered by the game.

This suggests a modification to our understanding of the constitution of the player-character, framing it as containing both a set of fixed 
CSs (the complete set of static mimetic elements, as well as those character actions which are pre-scripted) and a mechanism for the generation of further CSs that, during the course of a given playthrough, come together into a unified set of CSs which, together, are interpreted by the player in the form of a possible non-actual individual. The implication of this is that, if two players both play The Last of Us, two different sets of CSs will be produced, sharing many of their elements, but, crucially, not all, given that the sets include within them different respective sequences of player actions. Let us say that the first set of CSs, produced from the first playthrough, results in an image of a character we can call Joel1. Meanwhile, the second set of CSs, produced from the second playthrough, results in an image of a character we can call Joel2.

In other words, when speaking of a player-character as a possible non-actual individual, we are speaking specifically of the character as actualized in one given playthrough: before this actualization, there is no character to speak of, only the framework for one. Of course, this framework will, to a varying, but, in most cases, considerable degree, impose narrow limits upon the range of possible actualizations of the player-character. It is for this reason that it remains possible, as has been done throughout the articulation of this model, to continue to speak of the player-character as a fixed constant across its various possible actualizations in the complete set of possible playthroughs of a game. In any successful playing of Gone Home, Katie’s careful, investigative quality is going to emerge, as is Joel's stoic determination in any playing of The Last of Us. Saying that the player-character is entirely determined in the player's actualization, then, is as reductive as considering it a fixed, predetermined construct: any understanding of the player-character must take both of these aspects into account in conceptualizing it as an entity. This is the point Schrö and Thon suggest when arguing that "even though the game constructs the frame within which the gameplay will be realized [...] ludic events are not determined before the game is played” (2014).

The second observation to make in the relation of character to player 
concerns the question of mental acts. We have already observed a number of ways in which the mental acts of a player-character can be communicated to the player - for instance, through formal techniques such as the interior monologues utilized in games such as Thief or No More Heroes (Grasshopper Manufacture 2008), or through the way in which physical or verbal actions can serve as indications of mental acts, as in the case of Joel's decision regarding Ellie's future. However, if mental actions are perhaps the purest indication of the irreducible, individual interiority that constitutes the essence of a character - the "precious remainder" that Barthes identifies (1974, 190 ) once the simple accumulation of textual signs have all been taken into account, and which, as Ryan $(2006,8)$ and Eder $(2010,17)$ - then we need to keep in mind that the figure in question is one in which two such individual interiorities meet: that of the character and that of the player.

The intersection between the two in the same figure is a theme that requires more involved attention than it can be given here. For our current purposes, however, it is pertinent to consider to what extent we can speak of the player's own phenomenal experiences of the gameworld as being attributable, through a representative relation, to the player-character. In this sense - though a simple one-to-one attribution of the player's mental acts to the character is out of the question - we would need to adapt the structural-semiotic model of the player-character to include, say, the player's fear when hiding from a clicker in The Last of Us, or her shock and concern for Sam when noticing what appear to be bloodstains in the bath in Gone Home - considering these as being relevant not just as first-hand phenomenal experiences on the part of the player, but also, at the same time, as representative signs for equivalent mental acts on the part of the character.

\section{CONCLUSION}

It has been the intention of this paper to address the lack of a solid conceptual foundation for the notion of a "character" as it is used in the term "player-character", thereby filling a gap in the game studies 
discourse. In summary, the understanding of the player-character as a character that this paper proposes involves two primary insights. First, we highlighted the dual ontology of the character, as both a possible non-actual individual and as an accumulation of semiotic cues from which this individual emerges as an abstract construct. Secondly, a structural-semiotic model was proposed in order to trace the various medialities operating in unison to deliver these cues.

This paper should not be taken as proposing a privileging of the discourse of the player-character over the discourse of the avatar, or to suggest that thinking of the player-character covers everything we need to know about the relation between the player and the figure under her control. In fact, our concluding insight is that this semiotic structure cannot be considered in isolation, and that the player-character as a semiotic totality is only available once it is actualized by the player. The next theoretical step, then, would be to incorporate the notion of character back into the wider discourses of the playable figure, from which we extracted it at the start. Having now been more rigorously defined, and carrying with it the ontological and semiotic implications we have mapped out, this understanding of character can now be of service in game studies' tackling of the complexities - ontological, phenomenological, narrative and otherwise - of the playable figure.

\section{REFERENCES}

Aarseth, E. Cybertext. Baltimore: Johns Hopkins University Press, 1997.

Aarseth, E. "Doors and Perceptions: Fiction vs. Simulation in Games”. In Intermedialities, 9, 35-44. 2007.

Aarseth, E. “A Narrative Theory of Games." In Proceedings: Foundations of Digital Games 2012, Raleigh, NC, USA, May 29 June 1, 2012.

Barthes, R. S/Z, trans. R. Miller. New York: Hill and Wang, 1974. 
Bayliss, P. "Beings-in-the-Gameworld: Characters, Avatars and Players.” In Proceedings of the Fourth Australasian Conference on Interactive Entertainment: IE2007, Australasian Conference on Interactive Entertainment, Melbourne, Australia, 2007.

Bethesda Game Studios. The Elder Scrolls V: Skyrim [PC]. Bethesda Softworks, 2011.

Bioware. Mass Effect [PC]. Electronic Arts, 2007.

Bioware. Star Wars: The Old Republic [PC]. Electronic Arts, 2010.

Capcom Street Fighter IV [Arcade]. Self-released, 2008.

Chatman, S. Story and Discourse: Narrative Structure in Fiction and Film. Ithaca, NY: Cornell University Press, 1980.

Crytek. Crysis [PC]. Electronic Arts. 2007.

Eder, J. “Understanding Characters." In Projections 4, no. 1, pp. 16-40. 2010.

Eder, J., Jannids, F. and Scheider, "Characters in Fictional Worlds: An Introduction". In Characters in Fictional Worlds, edited Eder et al., pp. 3-66. Berlin and New York: De Gruyer, 2010.

Eidos Montreal. Deus Ex: Human Revolution [PC]. Eidos. 2011.

Fernández-Vara, C. “The Paradox Between Player Control and Player Character in Adventure Games”. Presented at the annual meeting of the International Communication Association (Boston, MA Online, May 25, 2011)

Forster, E.M. Aspects of the Novel. San Diego, CA: Harcourt Brace, 1995.

Frasca, G. "Rethinking Agency and Immersion: Videogames as a Means of Consciousness-Raising”. Paper presented at the ACM SIGGRAPH 2001, Los Angeles, US, 12-17 August 2001. Available 
at http://www.siggraph.org/artdesign/gallery/S01/essays/0378.pdf (accessed May 14, 2014).

The Fullbright Company. Gone Home [PC]. Self-released, 2013.

Gee, J.P. “Video Games and Embodiment.” Games and Culture 3, no. 3-4, pp.253-263, 2008.

Genette, G. Narrative Discourse, translated by J. E. Lewin. Ithaca, NY: Cornell University Press, 1980.

Grasshopper Manufacture. No More Heroes [Nintendo Wii]. Rising Star Games, 2008.

Heidbrink, H. "Fictional Characters in Literary and Media Studies: A Survey of the Research." In Characters in Fictional Worlds, pp. 67-110. 2010.

James, H. “The Art of Fiction.” In The Future of the Novel, edited by L. Edel, pp. 3-27. New York: Vintage, 1956[1884].

Järvinen, A. Games without Frontiers: Theories and Methods for Game Studies and Design. Doctoral Thesis. Acta Electronica Universitatis Tamperensis 701 Media Culture. University of Tampere, 2008.

Jørgensen, K. “'I’m Overburdened!': An Empirical Study of the Player, the Avatar, and the Gameworld" in Proceedings from DiGRA 2009: Breaking New Ground: Innovation in Games, Play, Practice and Theory. Brunel University, London, September 1-4, 2009.

Jørgensen, K. “Game Characters as Narrative Devices”, in Eludamos: Journal for Computer Game Culture 4, no. 2 pp. 315-331. 2010.

Klastrup, L., \& Tosca, S.P. ““Because it just looks cool!” Fashion as Character Performance: The Case of WoW', in Journal of Virtual Worlds Research 1, no. 3, pp. 4-17. 2009. 
Klevjer, R. What is the Avatar: Fiction and Embodiment in Avatarbased Singleplayer Computer Games. Doctoral thesis: University of Bergen, 2006.

Klevjer, R. "Enter the Avatar: The Phenomenology of Prosthetic Telepresence in Computer Games", in J.R. Sageng et al. (eds.), The Philosophy of Computer Games, Philosophy of Engineering and Technology 7, pp. 17-38. New York: Springer, 2012.

Lankoski, P., Heliö, S., \& Ekman, I. “Characters in Computer Games: Toward Understanding Interpretation and Design.” In Level Up: Digital Games Research Conference 2003 Conference Proceedings, edited by M. Copier and J. Raessens. Utrecht: Universiteit Utrecht, 4-6 November 2003.

Lankoski, P. "Player Character Engagement in Computer Games”, in Games and Culture 6, no. 4, pp. 291-391. 2011.

Linderoth, J. “Animated Game Pieces: Avatars as Roles, Tools and Props”, in Proceedings of the Aesthetics of Play Conference, Bergen, 14-15 October 2005.

Looking Glass Studios. Thief: The Dark Project [PC]. Eidos Interactive, 1998.

LucasArts . Full Throttle [PC]. Self-released, 1995.

LucasArts. The Curse of Monkey Island [PC]. Self-released, 1997.

Margolin, U. "The Doer and the Deed: Action as a Basis for Characterization in Narrative”. In Poetics Today 7, no. 2, pp.205-225. 1986.

Margolin, U. "Individuals in Narrative Worlds: An Ontological Perspective.” In Poetics Today 11, no. 4, pp.843-871, 1990.

Montfort, N. "Fretting the Player Character." In Second- 
Person, edited by P. Harrigan and N. Wardrip-Fruin, pp. 139-146. Cambridge, MA: MIT Press.

Mukherjee, S. "Vishnu and the Videogame”, in Proceedings of the 6th International Philosophy of Computer Games Conference, Madrid, January 29-31 2012.

Murray, J.H. Hamlet on the Holodeck. Cambridge, MA: MIT Press, 1997.

Naughty Dog Uncharted: Drake's Fortune [Playstation 3]. Sony Computer Entertainment, 2007.

Naughty Dog. The Last of Us [Playstation 3]. Sony Computer Entertainment, 2013.

Newman, J. “The Myth of the Ergodic Videogame.” In Game Studies 1, no.2, 2002. Available at http://gamestudies.org/0102/newman/ (accessed Feb. 2014)

Nintendo. Super Mario 64 [Nintendo 64]. Self-released, 1996.

Nintendo. The Legend of Zelda: The Ocarina of Time [Nintendo 64]. Self-released, 1998.

Palmer, A. Fictional Minds. Lincoln and London: University of Nebraska Press, 2004.

Perfect Entertainment. Discworld Noir [PC]. GT Interactive, 1999.

Phelan, J. Reading People, Reading Plots: Character, Progression and the Interpretation of Narrative. Chicago, IL: Chicago University Press, 1989.

Price, M. Forms of Life. New Hanve and London: Yale University Press, 1983.

Project Soul. Soul Calibur [Arcade]. Namco, 1998. 
Quantic Dream. Heavy Rain [Playstation 3]. Sony Computer Entertainment, 2010.

Quantic Dream. Beyond: Two Souls [Playstation 3]. Sony Computer Entertainment, 2013.

Rehak, B. "Playing at Being: Psychoanalysis and the Avatar." In The Video Game Theory Reader, edited by M.J.P. Wolf and B.Perron, pp. 103-127. London: Routledge, 2003.

Rimmon-Kenan, S. Narrative Fiction. London: Routledge, 1983.

Ryan, M.L. Avatars of Story. Minneapolis, MN: University of Minnesota Press, 2006.

Schröter, F., and Thon, J.N. "Video Game Characters: Theory and Analysis.” In Diegesis 3, no. 1, 2014.

Searle, J. Speech Acts. Cambridge: Cambridge University Press, 1969.

Sonic Team. Sonic the Hedgehog [Mega Drive]. Sega, 1991.

Team Ninja. Dead or Alive 3 [Xbox]. Tecmo, 2001.

Ubisoft Montpellier. Beyond Good \& Evil [Playstation 2]. Ubisoft, 2003.

Ubisoft Montreal. Deus Ex: Human Revolution [PC]. Ubisoft, 2010.

Valve. Half-Life [PC]. Sierra Entertainment, 1998.

Valve. Half-Life 2 [PC]. Electronic Arts, 2004.

Vella, D. "Spatialised Memory: The Gameworld As Embedded Narrative." In Proceedings of the Philosophy of Computer Games Conference 2011, Athens, Greece, April 6-9 2011.

Vella, D. "It’s A-Me/Mario: Playing as a Ludic Character." In 
Proceedings of the Foundations of Digital Games Conference 2013, Chania, Greece, May 14-17 2013.

Vella, D. "Player and Figure: An Analysis of a Scene in Kentucky Route Zero," in Proceedings of the Nordic DiGRA Conference 2014, Visby, Sweden, May 292014.

Waggoner, Z. My Avatar, My Self. Jefferson, NC: McFarland, 2009.

Westecott, E. “The Player Character as Performing Object”, in Proceedings from DiGRA 2009: Breaking New Ground: Innovations in Games, Play, Practice and Theory. Brunel University, London, September 1-4, 2009. Available at http://www.digra.org/wp-content/ uploads/digital-library/09287.43252.pdf (accessed Feb. 2014)

Yager Development. Spec Ops: The Line [PC]. 2K Games, 2012. 